\title{
ESTUDO DOS ALIMENTOS NA EDUCAÇÃO DE JOVENS E ADULTOS E O ENSINO DE QUÍMICA
}

\author{
STUDY OF FOODSTUFFS IN THE EDUCATION OF YOUNGSTERS AND \\ ADULTS AND THE CHEMISTRY TEACHING
}

\section{ACCIONES PARA PROMOVER LA ALFABETIZACIÓN CIENTÍFICA EN LA EDUCACIÓN DE JÓVENES Y ADULTOS}

\author{
Marcelo Franco LEÃO ${ }^{1}$ \\ Eniz Conceição OLIVEIRA ${ }^{2}$ \\ Cecília Vieira GUERRA ${ }^{3}$ \\ José Claudio DEL PINO ${ }^{4}$
}

\begin{abstract}
RESUMO: O presente texto relata uma intervenção pedagógica cujo objetivo foi avaliar se a abordagem contextualizada sobre alimentos associada ao desenvolvimento de estratégias inovadoras favorece o aprendizado de Química na Educação de Jovens e Adultos. A pesquisa, de caráter qualitativo, envolveu uma turma de $1^{\circ}$ Ano do Ensino Médio, constituída por 21 mulheres, do Centro de Educação de Jovens e Adultos "15 de outubro", de Barra do Bugres - MT. Para a realização deste estudo, a metodologia empregada buscou adequar as estratégias de ensino às reações dos participantes seguindo a sequência didática: motivação inicial, problematização, situação problema, conteúdos âncora, trabalhos de pesquisa em grupo e avaliação. Os instrumentos de coletas de dados utilizados foram as entrevistas e um questionário com todas as participantes, além das observações registradas em um diário. Para analisar os resultados utilizou-se a metodologia da Análise de Conteúdo. Das falas das participantes emergiram três categorias: favoreceu o aprendizado, a temática facilitou o entendimento e abordou aspectos interessantes. O uso de materiais concretos contribuiu para a compreensão dos conceitos da Química que muitas vezes são abstratos. Proporcionar um ambiente estimulante e envolvente é fundamental nos processos de ensino e de aprendizagem, pois cria condições para que as estudantes se relacionem com o objeto de estudo e construam conhecimentos.
\end{abstract}

Palavras-chave: Ensino de química. Educação de adultos. Estratégias de ensino.

\footnotetext{
${ }^{1}$ Doutorado em Educação em Ciências (UFRGS). Mestrado em Ensino (UNIVATES). Especialização em Orientação Educacional (DOM ALBERTO) e em Relações Raciais na Educação e Sociedade Brasileira (UFMT). Licenciatura em Química (UNISC) e em Física (UNEMAT). Professor do IFMT Campus Confresa. ORCID: http://orcid.org/0000-0002-9184-916X. E-mail: marcelo.leao@cfs.ifmt.edu.br

2 Doutorado e Mestrado em Química (UFRGS). Graduação em Química (UFRGS). Pós-doutorado em Ensino de Química (Universidade de Aveiro). Professora do Centro Universitário UNIVATES e orientadora nos PPGEnsino e Ensino de Ciências Exatas da UNIVATES. ORCID: http://orcid.org/00000003-0252-2243. E-mail: eniz@univates.br

3 Investigadora Doutorada no Centro de Investigação em Didática e Tecnologia na Formação de Formadores (CIDTFF), Departamento de Educação e Psicologia, Universidade de Aveiro (Portugal). ORCID: https://orcid.org/0000-0002-2560-165X. E-mail: cguerra@ua.pt

${ }^{4}$ Pós-doutorado em Ensino de Química (Universidade de Aveiro). Doutorado em Biomassa e Mestrado em Química (UFRGS). Graduação em Química (UFRGS). Professor do PPGEnsino da UNIVATES e do PPGQVS da UFRGS. ORCID: http://orcid.org/0000-0002-8321-9774. E-mail: jose.pino@univates.br
} 
ABSTRACT: This text reports on a pedagogical intervention that aimed to evaluate whether the contextualized approach on food to the subject associated to the development of innovative strategies favor the learning of Chemistry in Youngster and Adult Education. The research is of qualitative nature and involved a class from the 1st Year of Intermediate Education comprising 21 women at the "octuber 15th" Youngster and Adult Education Center in Barra do Bugres - MT. To carry out this study, the methodology employed sought to adjust the teaching strategies to participants' reactions, and follow the didactic sequence: initial motivation, questioning, problem situation, anchor contents, group research work, and evaluation. The data collection instruments used were the interviews and a questionnaire, in addition to observations recorded on a log. The results analysis employed the Content Analysis methodology. Three categories emerged from the participants' speeches: it favored learning, the theme facilitated understanding and covered interesting things. The use of concrete materials contributed to the understanding of Chemistry concepts, which oftentimes are abstract. El uso de materiales concretos contribuyó a la comprensión de conceptos de química que a menudo son abstractos. Providing a stimulant and involving environment is essential in the teaching and learning processes, since it brings conditions for students to relate with the object of study and build knowledge.

Keywords: Teaching of chemistry. Adult education. Teaching strategies.

RESUMEN: Este texto relata una intervención pedagógica cuyo objetivo ha sido evaluar si el abordaje contextualizado acerca de los alimentos asociado al desarrollo de estrategias innovadoras favorece el aprendizaje de Química en la Educación de Jóvenes y Adultos. La investigación, de carácter cualitativo, fue realizada con un grupo de ler. año de enseñanza secundaria, constituido por 21 mujeres del Centro de Educación de Jóvenes y Adultos "15 de octubre", de Barra do Bugres - MT. Para la realización de este estudio, la metodología empleada buscó adecuar las estrategias de enseñanza a las reacciones de los participantes y seguir la secuencia didáctica: motivación inicial, problematización, situación problema, contenidos clave, trabajos de investigación en grupo y evaluación. Los instrumentos utilizados para la recolección de datos fueron entrevistas y un cuestionario, además de las observaciones registradas en un diario. Para analizar los resultados se ha utilizado la metodología del Análisis de Contenido. De las declaraciones de las participantes emergieron tres categorías: favoreció el aprendizaje, la temática facilitó la comprensión y abordó aspectos interesantes. Proporcionar un ambiente estimulante y atractivo es fundamental en los procesos de enseñanza y aprendizaje, pues crea condiciones propicias para que las estudiantes se relacionen con el objeto de estudio y construyan conocimientos.

Palavras clave: Enseñanza de química. Educación de adultos. Estrategias de enseñanza.

\section{Introdução}

A prática pedagógica que se tem observado na maioria das salas de aula está longe de atender às necessárias transformações por estar baseada em metodologias tradicionais de ensino que não favorecem a produção do conhecimento, tampouco a transformação social. $O$ que se tem constatado é uma educação centrada no 
cumprimento de programas pré-estabelecidos sem a preocupação com a validade desses conhecimentos (LOPES, et al., 2007).

Diante dessa problemática, o papel do professor é preferencialmente o de ensinar a perguntar em vez de fornecer respostas. Entretanto, uma boa pergunta requer a utilização do conhecimento prévio de maneira significativa, dada a grande quantidade de informações com que o estudante interage, como generalidades, especificidades ou trivialidades disponibilizadas pelos meios de comunicação, a saber: internet, TV, revistas, jornais, cinema e rádio, entre outros. Neste sentido, é fundamental que o estudante tenha a percepção de como selecionar e analisar quais questões são relevantes à sua aprendizagem (saber pensar), fazendo com que ele desenvolva uma percepção crítica a respeito da sociedade e do contexto em que está inserido (DEMO, 2001).

Assim sendo, faz-se necessário repensar o processo pedagógico de ensino e aprendizagem para que seja proporcionado ao estudante um ambiente mais envolvente no qual ele possa desenvolver suas habilidades cognitivas e aprender de maneiras diferentes o que é solicitado pela instituição educacional. Contudo, não se pode pensar em sucesso didático se o educador não possuir um eixo orientador de suas ações. Segundo Anastasiou e Alves (2004), o professor precisa ressignificar seu trabalho por meio de mudanças metodológicas a fim de que aconteçam avanços significativos no processo de ensino e de aprendizagem e na formação humana.

Posto isso, cumpre ressaltar que o presente texto é resultado dos estudos e discussões em torno dos processos de ensino e aprendizagem ocorridos durante o desenvolvimento da pesquisa de mestrado (LEÃO, 2014). Esses estudos revelaram a necessidade de que para atender a este novo contexto que se configura é preciso desenvolver em sala de aula diversificadas estratégias de ensino, dentre as quais são lembradas: tempestade cerebral, elaboração de mapas conceituais, estudos em pequenos grupos, estudos dirigidos e outras. Por sua vez, o objetivo foi avaliar se abordar a temática alimentação como forma de contextualizar o estudo da Química, por meio de estratégias de ensino diversificadas, favorece a construção de aprendizados com significado para estudantes da Educação de Jovens e Adultos.

\section{Reflexões sobre os processos de ensino e aprendizagem}

A concepção construtivista considera que, no decorrer das situações de ensino, os referenciais e teorias que embasam determinado conhecimento servem como guia, 
fundamento e justificativa para a atuação dos educadores; porém, estão subordinados a um conjunto de decisões que não são de responsabilidade exclusiva do professor, pois o estudante, enquanto sujeito da aprendizagem, participa da tomada de decisões (COLL; MARTINI; MAURI, 2009). Segundo a abordagem construtivista, no processo de ensino, os referenciais e teorias não determinam a ação em si, mas funcionam como eixos norteadores dessa ação.

Nessa perspectiva, o pensamento estratégico embasado em uma determinada teoria proporciona ao professor dirigir e regular as situações de aprendizagem e ajustálas aos objetivos que persegue (BORDENAVE; PEREIRA, 2005; GIL, 2012). Assim, a importância dessa referência se dá pelo fato de ela fornecer instrumentos de análise e reflexão sobre a prática. Os marcos referenciais da ação mediadora se mostrarão adequados à medida que possam dar alguma explicação sobre as interrogações que surgem nos processos de ensino e aprendizagem (PINHEIRO; GONÇALVES, 2001).

O fazer docente se tornou mais trabalhoso e, por que não dizer, mais difícil. De fato, ele necessita de uma elaboração mais consciente e direcionada, de um pensar mais profundo sobre para que, o que e como ensinar (FONSECA, 2008). O tempo do improviso e da receita pronta que tem se repetido ano após ano já se desgastou; é preciso repensar, refazer, inovar. Recomeçar a sonhar sim, mas com os pés no chão, conscientes de que um pequeno passo já é uma vitória, de que errar faz parte do processo e pode ser o ponto de partida para um novo tentar. Isso significa que ser estrategista é saber o que se pretende atingir, requer que se tenha clareza sobre aonde se pretende chegar com o processo ensino.

Na concepção de Demo (2001), o professor mediador que busca, em suas práticas, ensinar a pensar, é aquele que motiva os estudantes, chama a atenção e critica quando necessário, aponta caminhos e não dá respostas prontas. Assim, abre oportunidades para que o indivíduo conquiste sua autonomia.

Em seus estudos, Bordenave e Pereira (2005) esclarecem que ensinar não é o mesmo que aprender e que apenas uma parte de tudo o que é ensinado o estudante efetivamente aprende. O ensino é visto pelos autores como resultante das relações de acompanhamento da aprendizagem dos alunos, do conhecimento aprofundado do assunto a ser ensinado e das técnicas didáticas que empregará. Ensinar consiste na resposta planejada diante das exigências do processo de aprendizagem (BORDENAVE; PEREIRA, 2005; FONSECA, 2008). 
Segundo Pimenta e Anastasiou (2002, p. 195), "a respeito do método de ensinar e fazer aprender (ensinagem) pode-se dizer que ele depende, inicialmente, da visão de ciência, de conhecimento e do saber escolar do professor". Em outras palavras, são determinantes as concepções epistemológicas e pedagógicas que os docentes têm sobre o ensino e a aprendizagem. No pensamento dos autores supracitados, o ensino está relacionado com a prática e o saber do professor, ou seja, para eles, o sucesso na aprendizagem está vinculado diretamente à ação pedagógica do educador.

No entendimento de Bordenave e Pereira (2005), para se estabelecer uma estratégia didática, dois conhecimentos são essenciais: experiências de aprendizagem e atividades de ensino e aprendizagem. É necessário que os estudantes se exponham a certas experiências - problemas reais ou representação deles - capazes de induzir as mudanças desejadas. Para o professor oportunizar a vivência dessas experiências, ele precisa estruturar atividades que promovam situações de aprendizagem.

De fato, é importante a escolha das atividades de ensino, pois elas podem influenciar o crescimento do estudante como pessoa. Enquanto os conteúdos informam, os métodos formam, daí a importância de proporcionar um ambiente estimulante aos estudantes (PINHEIRO; GONÇALVES, 2001). Desse modo, o uso do termo "estratégias de ensino" se refere aos meios utilizados pelos docentes na articulação do processo de ensino de acordo com cada atividade e os resultados esperados.

É exatamente nesse momento que o docente assume a postura de interlocutor do processo, pois não basta ter as informações sem estabelecer conexões na hora oportuna, isto é, na resolução de problemas. Isso é reforçado por Gomez (2004) quando ele afirma que o papel principal do professor é ajudar o aluno a interpretar essas informações, a relacioná-las e contextualizá-las.

Outro aspecto a ser considerado, segundo Anastasiou e Alves (2004, p. 71), é que:

As estratégias visam à consecução de objetivos, portanto, há que ter clareza sobre aonde se pretende chegar naquele momento com o processo de ensinagem. Por isso, os objetivos que norteiam devem estar claros para os sujeitos envolvidos - professores e alunos - e estar presentes no contrato didático, registrado no Programa de Aprendizagem correspondente ao módulo, fase, curso [...].

Os autores enfatizam que, para ensinar, é preciso deixar transparecer a todos os envolvidos aonde se pretende chegar, ou seja, qual a finalidade desse processo 
educativo. Isso significa que não basta elencar conteúdos e definir o método; mas que os atores desse processo tenham objetivos comuns e estejam envolvidos na sua execução.

As estratégias ou dinâmicas que abrangem atividades em grupos, segundo Gil (2012), desenvolvem capacidades que são impossíveis de ocorrer com técnicas individuais. Por sua vez, as coletivas oportunizam estudar um problema em equipe, desenvolvem colaboração, debate, discussão e estabelecimento de relações entre o tema, as experiências e os conhecimentos pré-existentes em suas estruturas cognitivas.

Os vários aspectos levantados sobre o tema ampliam o universo intelectual do aprendiz, que avança e aprende mais do que se estivesse estudando sozinho. Em outras palavras, a produção coletiva é mais rica que a individual por agregar diferentes pontos de vista, isto é, são várias interpretações sobre um mesmo objeto, o que aumenta a flexibilidade mental do aluno ao reconhecer a diversidade de interpretações sobre o mesmo assunto (GIL, 2012).

Uma estratégia de ensino que estimula a produção coletiva é a tempestade cerebral. Anastasiou e Alves (2004, p. 82) definem essa metodologia como "uma possibilidade de estimular a geração de novas ideias de forma espontânea e natural, deixando funcionar a imaginação. Não há certo ou errado. Tudo o que for levantado será considerado, solicitando-se, se necessário, uma explicação posterior do estudante".

Ao corroborar esse conceito, Fonseca (2008) apresenta a tempestade cerebral, ou mental, como uma estratégia que estimula o pensamento rápido, espontâneo e criativo. O autor reafirma que todas as informações levantadas devem ser consideradas e acompanhadas pela justificativa do estudante que as produziu.

Outra estratégia de produção coletiva defendida por Anastasiou e Alves (2004) é a elaboração de mapas conceituais. Estes são esquemas gráficos para representar a estrutura básica de partes do conhecimento sistematizado que se objetiva construir. Tais esquemas podem ser entendidos como redes de conceitos e proposições relevantes de determinado conhecimento.

A seleção dos conceitos e proposições relevantes, bem como a composição e organização dos mapas conceituais, obedecem aos critérios da teoria de Ausubel (2003). Nas palavras de Faria (1995, p.1):

Os mapas conceituais podem ser concebidos como instrumentos para cartografar o conjunto de ideias aprendidas em uma área específica por alunos ou por sujeitos de uma 'área específica', por 'alunos ou' por 'sujeitos' de uma pesquisa educacional. 
Cabe lembrar que a aprendizagem significativa é um processo que se efetiva a partir de sucessivas interações e os conceitos vão sendo elaborados, desenvolvidos e diferenciados (AUSUBEL, 2003). Nessa perspectiva, a aprendizagem de um conceito é facilitada quando se introduzem primeiramente os elementos mais gerais e mais inclusivos e, logo após, de maneira progressiva, os termos detalhados e especificados. Por isso, um mapa conceitual é a ferramenta que organiza os conteúdos e ideias, além de dar visibilidade do objeto de estudo ao aprendiz.

Um critério a ser observado na elaboração de mapas é que as ideias devem ser apresentadas de modo a formar uma frase completa, uma proposição, ou seja, têm que expor uma característica autoexplicativa. As proposições são constituídas por um conceito mais amplo (substantivo), por uma palavra ou frase de ligação, geralmente contendo verbo, e por um conceito mais específico. Isso significa que, ao serem conectados por verbos ou frases de ligação, dois ou mais substantivos estabelecendo uma unidade semântica, forma-se uma proposição (MOREIRA, 2006).

Assim sendo, sugere-se que as ideias mais gerais e inclusivas sejam apresentadas quando se propõe o estudo de um novo conteúdo. Em um segundo momento, passa-se a trabalhar com conceitos menos gerais e mais específicos, que serão diferenciados progressivamente.

Moreira (2006) define mapas conceituais como diagramas bidimensionais que indicam relações entre conceitos, ou seja, seu objetivo é representar as relações entre os conceitos por meio de proposições em um determinado tópico. Segundo o autor, os mapas conceituais podem ser utilizados como estratégias de ensino, avaliação, estudo, entre outros.

\section{Procedimentos metodológicos}

O estudo se trata de uma pesquisa-ação, cuja capacidade de aprendizagem é aproveitada e enriquecida em função das exigências da ação em torno da qual se desenrola a investigação. Esse tipo de pesquisa tem como característica o envolvimento de todos na problemática estudada; assim, tanto o pesquisador como os participantes, aprendem durante o processo (THIOLLENT, 2005). Ela é baseada na descrição, observação e ação de situações reais. 
Moreira (2011) caracteriza a pesquisa-ação como um estudo de caso interpretativo, pois permite coletar dados e descrições ricas que serão utilizadas para desenvolver categorias conceituais nas quais o foco está em gerar mudanças no caso em estudo. Para isso, é preciso que o pesquisador reúna o maior número possível de informações sobre o objeto em questão e ou teorizar o fenômeno investigado.

A abordagem metodológica da pesquisa é qualitativa. Segundo Lüdke e André (2013), ela permite compreender a trama intrincada do que ocorre numa situação microssocial, pois coloca o pesquisador no meio da cena investigada, dela participa e toma partido. Seu desenvolvimento ocorreu no Centro de Educação de Jovens e Adultos, denominado CEJA "15 de Outubro", na cidade de Barra do Bugres/MT, Brasil.

O público participante totalizou vinte e uma estudantes de uma turma do $1^{\circ}$ ano do Ensino Médio, do período vespertino, com faixa etária entre dezoito e quarenta e seis e anos. Seis delas desempenhavam atividade formal; as demais desenvolviam tarefas do lar. Algumas trabalhavam com vendas e faziam artesanato para vender e complementar a renda familiar. O tempo afastado da escola variava de dois a vinte e cinco anos. Cabe registrar que no período vespertino havia somente uma turma de $1^{\circ}$ ano e que o professor/pesquisador somente atuava nesse nível de ensino, ou seja, era o primeiro contato com as estudantes envolvidas no estudo.

A execução da prática de ensino ocorreu no terceiro trimestre do calendário escolar de 2013, no total de cinquenta horas de aula. A estrutura curricular da intervenção pedagógica abordou a temática "Alimentos" por acreditar que o conteúdo é potencialmente significativo para o contexto social dos estudantes. Esta proposta curricular pode ser observada no Quadro 1.

Quadro 1 - Proposta curricular diferenciada.

\begin{tabular}{|c|l|}
\hline Proposta Curricular Diferenciada & \multicolumn{1}{|c|}{ Conteúdos de referência relacionados } \\
\hline$\bullet \quad \begin{array}{l}\text { A importância dos alimentos, } \\
\text { sua origem e principais } \\
\text { características. }\end{array}$ & $\begin{array}{l}\text { Conceito de alimentos e suas origens; Estudo dos materiais; } \\
\text { Substâncias puras e misturas; Grupos Alimentares e Pirâmide } \\
\text { Alimentar. }\end{array}$ \\
\hline$\bullet \quad \begin{array}{l}\text { Dieta alimentar e valor calórico } \\
\text { dos alimentos. }\end{array}$ & $\begin{array}{l}\text { Classificação dos Alimentos; Dieta alimentar equilibrada; } \\
\text { Roda dos alimentos; Valor calórico dos alimentos e } \\
\text { Benefícios de uma alimentação saudável. }\end{array}$ \\
\hline$\bullet \quad \begin{array}{l}\text { Boas práticas no preparo de } \\
\text { alimentos. }\end{array}$ & $\begin{array}{l}\text { Boas práticas no preparo; Higiene; Tipos de contaminação; } \\
\text { Agentes contaminantes; Preparo de soluções e Vitaminas. }\end{array}$ \\
\hline $\begin{array}{l}\text { Conservação dos alimentos por } \\
\text { refrigeração: como organizar a } \\
\text { geladeira. }\end{array}$ & $\begin{array}{l}\text { Conservação de alimentos; Maneira correta de armazenar os } \\
\text { alimentos; Embalagens: características e validade; } \\
\text { Conservação pelo frio e Convecção térmica. }\end{array}$ \\
\hline
\end{tabular}


- $\quad$ Processamento de alimentos e comercialização.

- $\quad$ Reações químicas que ocorrem com alimentos.

- A substância água e o processo para torná-la potável.

- A relação entre os nutrientes e a composição celular.

- A composição química dos alimentos.

- $\quad$ Viagem ao interior dos alimentos: do micro ao macro.
Processamentos de alimentos; Mudanças de estados físicos; Aparência e estética do produto e Padronização na produção.

Tipos de reações químicas; Evidências da ocorrência de uma reação; Identificação de reagentes e produtos; Indicadores, catalisadores, meio reacional e Inibição enzimática.

Funções da água no corpo e no preparo de alimentos; Tratamento e potabilidade da água;

Processos de separação das misturas e Análises químicas para o controle de qualidade.

Moléculas orgânicas e inorgânicas da célula; Composição química da célula; Célula procarionte e eucarionte; Organelas e suas funções; Célula Animal e Célula Vegetal.

Sais minerais; Elementos químicos; Percentual de elementos que compõe o corpo humano e os alimentos e Tabela Periódica dos elementos.

Estrutura e organização dos materiais; Modelos atômicos de Dalton, Thomson e Rutherford-Bohr; Eletrosfera e núcleo; Prótons, elétrons e nêutrons.

Fonte: Elaborado pelos autores (2013).

Como metodologia pedagógica, buscou-se utilizar a construção dialogada, na qual ocorre a interação professor/alunos/conteúdos, em um ir e vir entre ação, reflexão, ação. A ação docente, no decorrer das atividades, aproximou-se dos passos sugeridos por Santos (2008): dar sentido ao conteúdo; especificar; compreender; definir; argumentar; discutir e levar para a vida. As aulas foram planejadas observando a concepção construtivista de aprendizagem, apresentada na Figura 1.

Figura 1 - Procedimentos adotados no desenvolvimento das aulas.

\section{SEQUÊNCIA DIDÁTICA}

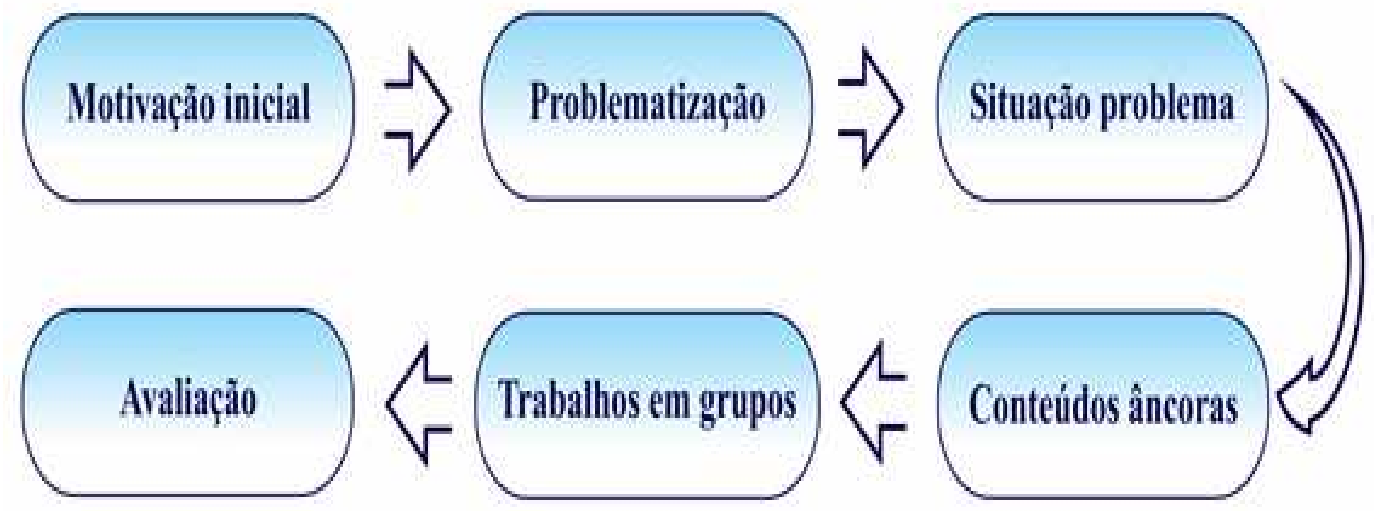


Fonte: Elaborado pelos autores (2013).

O presente artigo descreve uma atividade desenvolvida durante a realização da pesquisa. Trata-se das discussões em torno da importância dos alimentos, sua origem e principais características.

A motivação inicial, que podia ser uma notícia ou um acontecimento do cotidiano, serviu para expor o assunto e estimular as estudantes para o estudo. Utilizouse a reportagem do Jornal Folha de São Paulo, de 28 de setembro de 2013, que relata a supersafra de milho em Mato Grosso.

A problematização contextualizou o objeto de estudo por meio de questionamentos, fato que envolveu as alunas com o tema, dando sentido à proposta Nesse seguimento, problematizou-se o assunto mediante os seguintes questionamentos: O que são alimentos? Qual a origem dos alimentos? Que papel eles desempenham no organismo? Em que a Química influencia na obtenção dos alimentos?

. Na sequência, apresentou-se uma situação-problema. Ato contínuo, solicitou-se que cada estudante proferisse uma palavra sobre a seguinte situação-problema: Por que necessitamos nos alimentar? As respostas para essa situação foram coletadas por meio da estratégia tempestade cerebral (ANASTASIOU; ALVES, 2004, FONSECA, 2008).

Por meio da tempestade cerebral, as estudantes tiveram a oportunidade de expor suas ideias sobre o assunto, tais como: "ter saúde, para sobreviver, para formar o corpo, pelos nutrientes, para funcionamento do corpo, fonte de energia, para ter força, para se movimentar, para crescer, ficar forte, porque é bom comer, por necessidade" (Diário de bordo).

$\mathrm{O}$ fato é que utilizar a problematização por meio dos questionamentos apresentados possibilitou verificar os conhecimentos prévios das participantes a respeito do assunto, o que, segundo Ausubel (2003), significa identificar os itens, na "casa do tesouro", do conhecimento na estrutura cognitiva.

Essa dinâmica, além de envolvente, valoriza a capacidade criativa do discente. Como já abordado anteriormente, não há certo ou errado, ou seja, todas as informações são válidas para conhecer o que a estudante pensa sobre o assunto. Nesse seguimento, apresentam-se os conteúdos âncoras apresentados no Quaro 1, os conhecimentos de referência trazidos pelo professor. Momentos de reflexão sobre textos, pesquisas e debates sobre o assunto são algumas das estratégias empregadas para valorizar a cooperação. Por fim, foi proposta atividades avaliativas como a elaboração de relatórios, fluxogramas ou mapas conceituais (FARIA, 1995; MOREIRA, 2006). 
Cumpre relatar que o fluxograma e os mapas conceituais foram construídos coletivamente no quadro e registrados no diário. Para transcrever os mapas, usou-se o software livre CmapTools. Os relatórios das atividades experimentais foram entregues de forma manuscrita ao professor, e alguns deles, transcritos e analisados como resultados da pesquisa.

A utilização da tempestade cerebral como estratégia logo no início das aulas foi intencional, pois ela serviu para levantar os conhecimentos prévios das participantes, além de estimular o pensamento rápido, espontâneo e criativo sobre o objeto de estudo, assim como a empregada na finalização das aulas (construção coletiva no quadro de mapas conceituais ou fluxogramas). Tais estratégias serviram para que as estudantes expressassem, de forma sintética, os conceitos e significados construídos durante o desenvolvimento das atividades. As informações coletadas, no início e no encerramento das aulas, justificaram esse propósito, já que demonstraram o quanto a construção conceitual foi enriquecida com a prática.

Ao término do debate, apresentaram-se, por meio de slides, os conteúdos âncoras para embasar o estudo sobre o assunto. Foram trabalhados os conceitos de alimentos, sua função, origem, grupos alimentares e pirâmide alimentar utilizada no Brasil.

Os alimentos foram conceituados e divididos em grupos de acordo com a função que desempenham no organismo (construtores, reguladores, energéticos e funcionais). As características e os representantes de cada grupo foram apresentados em slides. A pirâmide alimentar utilizada no Brasil contém importantes dados sobre a alimentação (PHILIPPI, et al., 1999), sendo a característica de cada grupo de alimento discutida de forma mais aprofundada em aula.

Após a apresentação da pirâmide, foi proposta uma discussão tendo como enfoque principal a classificação de cada alimento, sua função no organismo e a proporção necessária de cada um deles por meio do número de porções para uma dieta equilibrada. Partiu-se, então, da contextualização dos conteúdos escolares como princípio educativo.

Para finalizar o encontro, justificou-se o motivo pelo qual os alimentos foram eleitos como tema para nortear as aulas de Química: fazerem parte integral da vida de todos. Para a aula seguinte, solicitou-se que cada estudante trouxesse de casa um alimento da pirâmide a fim de analisá-lo e, posteriormente, utilizá-lo em outra estratégia. 
No encontro seguinte, antes do início da atividade, foi colocada uma grande mesa no centro da sala de aula para que os alimentos solicitados ficassem sobre ela dispostos. Após a retomada das discussões da aula anterior, deu-se encaminhamento aos trabalhos. Em grupos, as alunas dirigiram-se à mesa e classificaram cada um dos alimentos presentes quanto à origem: animal, vegetal ou mineral (Figura 2).

Figura 2 - Classificação dos alimentos quanto à sua origem.

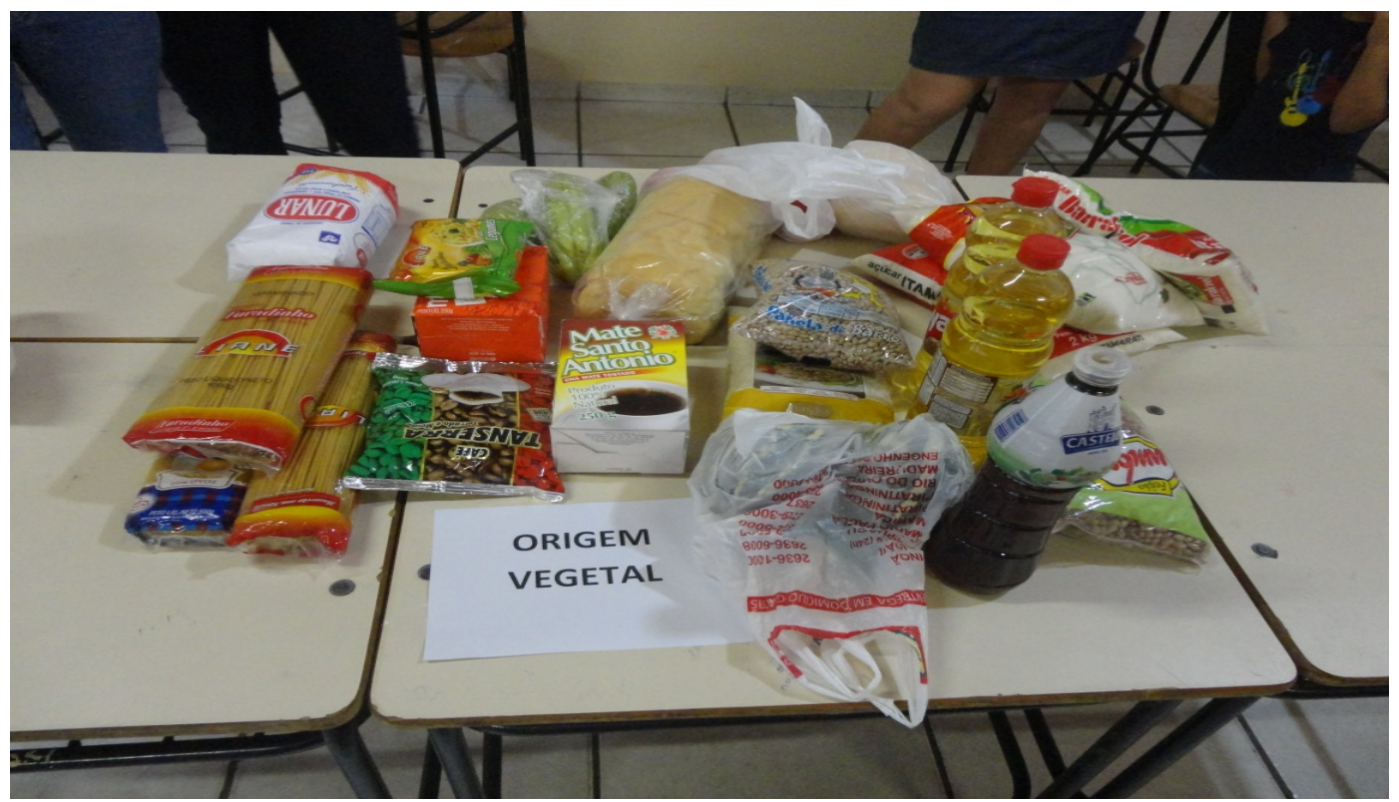

Fonte: Acervo pessoal dos autores (2013).

$\mathrm{Na}$ ocasião, questionaram-se os motivos pelos quais a maior parte dos alimentos apresentados pelas participantes ser de origem vegetal. As justificativas listadas foram: A cultura influencia a alimentação das pessoas; existem grupos que não se alimentam com produtos de origem animal; os alimentos de uma mesma origem podem apresentar características diferentes (Diário de bordo). Como exemplos, temos o trigo - um cereal energético - e o brócolis - uma hortaliça apreciada pelo alto teor de vitaminas -, ambos com características reguladoras.

Em seguida, as estudantes dispuseram os alimentos, anteriormente categorizados quanto à origem, de maneira a preencher a pirâmide construída em madeira. Cada uma selecionou um deles, avaliando se pertencia à prateleira dos energéticos, dos reguladores, dos construtores ou dos superenergéticos. A justificativa da escolha foi apresentada ao grupo que avaliava se realmente tal característica condizia com o relato. A atividade serviu para reforçar a disposição da pirâmide alimentar utilizada no 
país e suas proporções para o fornecimento de uma dieta equilibrada. A Figura 3 representa a conclusão desse momento.

Figura 3 - Construção da pirâmide alimentar.

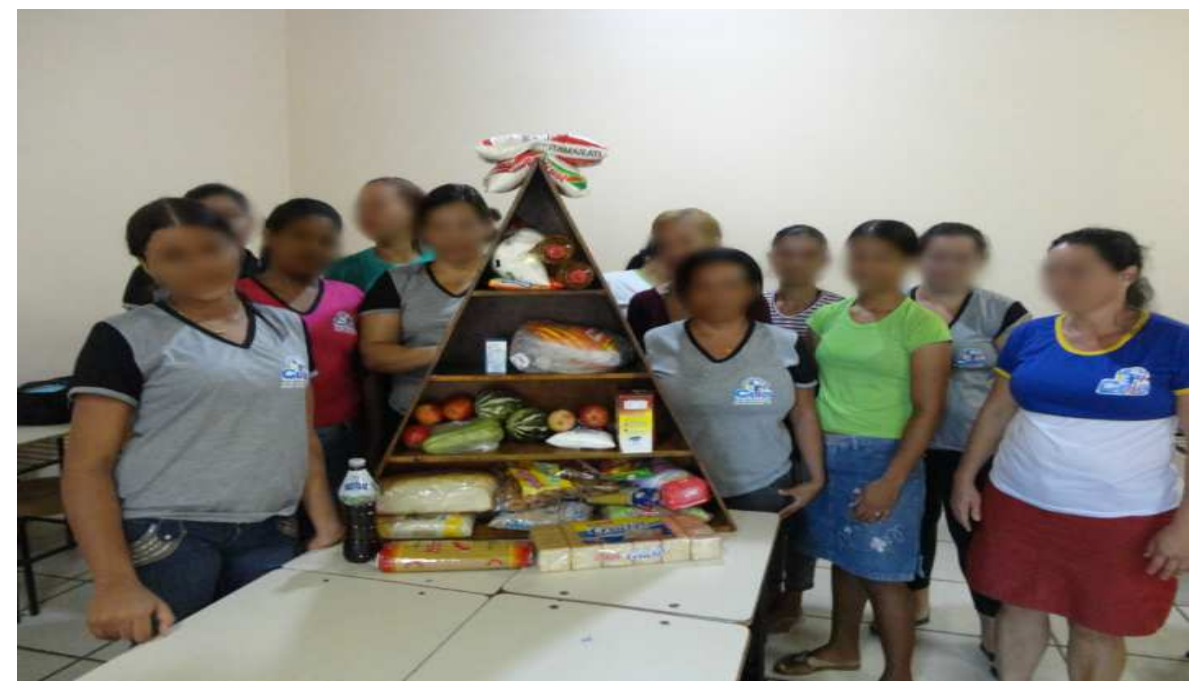

Fonte: Acervo pessoal dos autores (2013).

Após socializar os resultados, a classe reelaborou o conceito sobre alimentos. Para sistematizar os conhecimentos construídos, foi produzido, no quadro, de forma colaborativa, um mapa conceitual (Figura 4).

Figura 4 - Sistematização conceitual da temática abordada.

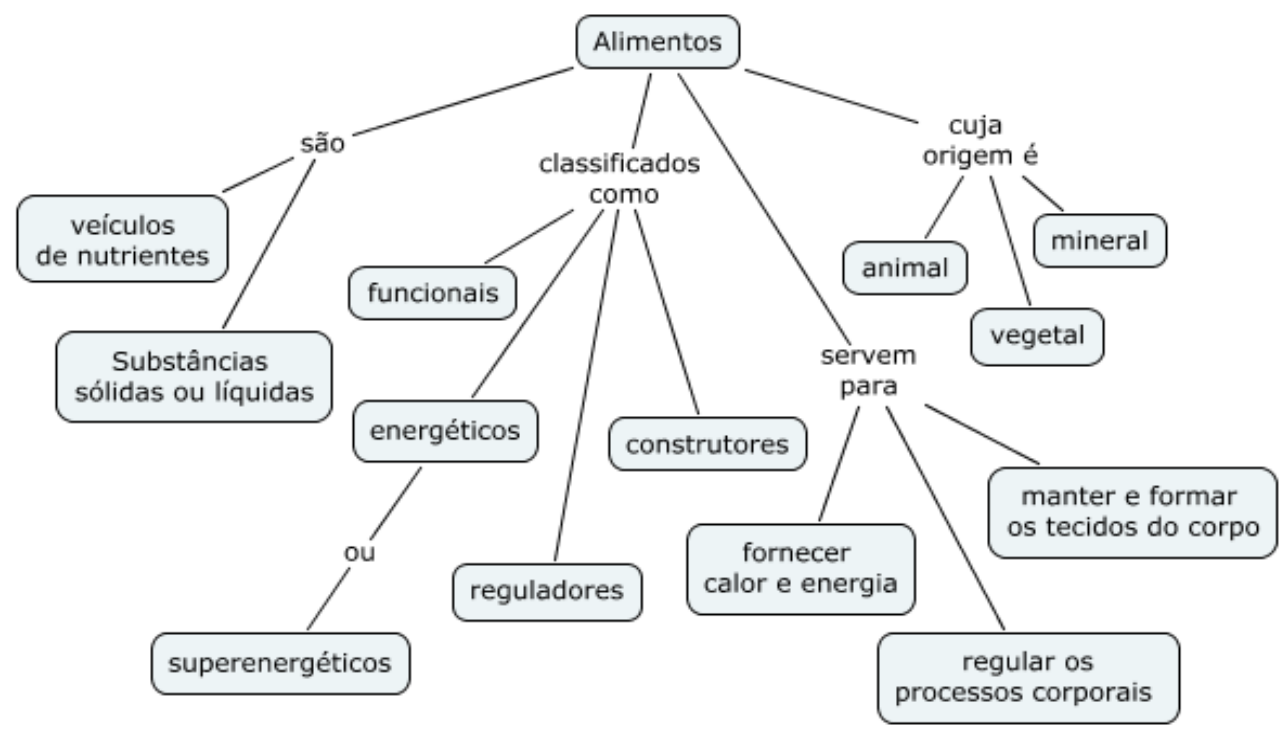

Fonte: Elaborado pelos autores baseado nos dados coletados na pesquisa (2013). 
Com a elaboração do mapa conceitual foi possível constatar que atividades coletivas favorecem a colaboração, oportunizam a troca de ideias, o redimensionamento dos saberes já existentes e o desenvolvimento de novos. O trabalho coletivo é essencial para a educação, uma vez que possibilita uma construção conceitual mais rica (GOMEZ, 2004) e organiza a relação entre os conceitos estudados (MOREIRA, 2006; FARIA, 1995).

Para a coleta de dados foram utilizadas as entrevistas semiestruturadas e um questionário de avaliação da prática desenvolvida. Esse questionário continha as seguintes perguntas: 1) Como você avalia as aulas de Química deste trimestre? 2) O que mais você gostou ou aprendeu no decorrer desse estudo? 3) O que pode melhorar para as próximas aulas de Química? 4) O que deve continuar? 5) No que contribuiu as aulas de Química deste trimestre em sua vida? Além disso, adotou-se um diário para registros das atividades.

A metodologia empregada para analisar os dados foi a Análise de Conteúdo, que Bardin (2012, p. 38) define como "um conjunto de técnicas de análise das comunicações que utiliza procedimentos sistemáticos e objetivos de descrição do conteúdo das mensagens". Dito de outro modo, essa técnica procura conhecer a mensagem que está por trás das palavras, ou seja, revelar outras realidades contidas nas mensagens. A discussão dos dados foi feita sob a luz do referencial teórico, entre eles Ausubel (2003), Bordenave e Pereira (2005), Demo (2001) e outros.

Cumpre destacar que, após apresentação dos objetivos e métodos que seriam adotados nessa pesquisa, as estudantes assinaram o Termo de Consentimento Livre e Esclarecido, por meio do qual se comprometeram a participar voluntariamente das atividades propostas, além de autorizarem a utilização dos dados, inclusive a da imagem. Para garantir o anonimato, seus nomes foram substituídos pelas siglas E1 (Estudante 1), E2 (Estudante 2), E3 (Estudante 3) e assim sucessivamente.

\section{Resultados e discussões}

A análise dos dados coletados, por meio da entrevista semiestruturada, revelou o quanto a intervenção pedagógica foi significativa para o estudo de Química por meio dos alimentos. Desses dados, emergiram três categorias: favoreceu o aprendizado, a temática facilitou o entendimento e abordou coisas interessantes. 
Nesse seguimento, agruparam-se as informações comuns existentes nas mensagens referentes à avaliação da prática pedagógica, bem como os aspectos considerados mais importantes no seu desenvolvimento. A primeira categoria que emergiu foi em relação ao favorecimento da aprendizagem. Sobre isso, algumas participantes declararam:

"Muito boas, apesar de pouco tempo, deu para aproveitar bastante. Que bom que tivessem mais aulas como essas" (E4).

"Para mim, foi ótimo, apenas que eu tive pouca frequência na sala de aula, apesar de que os dias em que eu estudei foi muito bom, pois aprendi muitas coisas" (E5).

“Foi boa, aprendemos muitas coisas que não sabíamos, foram aulas divertidas e com grandes aprendizados. Que bom que tivemos aulas na prática, foi muito boa a visita que fizemos ao asilo e à ETA para ver como é o tratamento da água que consumimos" (E7).

Eu avalio que foram umas aulas ótimas com muito aprendizado $e$ conhecimento" (E12).

"Foram aulas muito construtivas e nos levaram a aprender um pouco mais do que é a Química e sua importância em nossa vida” (E21).

Observa-se que o estudo da Química por meio de alimentos favoreceu a construção do conhecimento das participantes. Segundo Coll, Martini e Mauri (2009), quando o estudante é motivado pelo processo educativo, ele aprende de tal maneira que se envolve na aprendizagem. Já Demo (2001) afirma que a educação contemporânea combina com emancipação, ou seja, é aquela que leva o aluno a pensar por conta própria, que vai além de um mero repasse de informações, promovendo, dessa forma, a aprendizagem com significado. Por sua vez, Ausubel (2003) assegura que a Aprendizagem Significativa permite que os discentes realizem uma leitura crítica da realidade e estabeleçam relações entre os conhecimentos científicos estudados com suas práticas cotidianas.

Outra categoria que emergiu das respostas referentes à avaliação do desenvolvimento dessa prática de ensino foi o tema do estudo - alimentos -, julgado pelas estudantes como significativo, contribuindo para o aprendizado dos conceitos químicos. Pelas enunciações, evidencia-se que estudar Química por meio dos alimentos facilita a compreensão dos fenômenos cotidianos e favorece o estabelecimento de 
relações entre os conteúdos estudados com suas práticas de vida. A transcrição de algumas respostas das participantes comprovam a afirmação:

"Muito boas, pois aprendi coisas que não sabia sobre os alimentos, que facilitaram meu aprendizado. Gostei muito” (E3).

"Achei significativo como a atividade dos elementos químicos por conseguirmos separar as coisas, por exemplo, os produtos e alimentos, interessante que até então achava que química fosse pior coisa, pois não entendia seu significado e agora entendo" (E10).

"Muito interessante foi perceber que os alimentos são constituídos por elementos químicos e também nós temos a mesma composição” (E18).

As declarações acima transcritas permitem evidenciar que o assunto "alimentos" fazia parte do cotidiano das estudantes, o que favoreceu o seu envolvimento, condição para ocorrer a aprendizagem significativa (AUSUBEL, 2003). Por sua vez, Santos (2008) defende uma prática de ensino que valorize os conhecimentos prévios dos alunos e que dê condições para que os conceitos construídos sejam empregados na resolução de problemas. Já para Bordenave e Pereira (2005), é preferível que o professor, em suas aulas, adote assuntos que contemplem a área de interesse dos estudantes e que estejam intimamente ligados ao objetivo da aprendizagem, ou seja, ter uma temática considerada envolvente é um incentivo a mais para pesquisar e se inteirar sobre ela.

A última categoria - abordou coisas interessantes - apresenta aspectos que agradaram às participantes, motivo pelo qual foram apontadas como aulas e/ou assuntos que despertaram o interesse pelo estudo. Seguem algumas respostas concedidas pelas alunas que demonstram esse aspecto:

“Foram bastante interessantes, muito proveitosas, aprendi muito sobre reações químicas, aprendi muito com as experiências” (E1).

"Uma experiência interessante que vou levar para minha vida, para o meu cotidiano. Porque a Química está em qualquer lugar onde nós vivemos nesse universo" (E9).

“Eu avalio como a nota 10. Foi tudo muito interessante” (E14).

"Interessante saber que o que estudávamos eram coisas que estavam acontecendo no dia a dia e em outros lugares" (E17).

As declarações das estudantes corroboram o pensamento de Santos (2008) quando o autor afirma que o ser humano se envolve com algo quando julga interessante, 
sendo uma das condições básicas para ocorrer a aprendizagem. Como já mencionado, o interesse garante a atenção do aluno sobre o objeto em estudo, levando-o a aprofundar o seu conhecimento. De fato, proporcionar um ambiente estimulante e envolvente é fundamental nos processos de ensino e aprendizagem, pois cria condições para que os estudantes se relacionem sistematicamente com o objeto de estudo e mudem suas estruturas cognitivas, tais como a habilidade de interagir com os diferentes contextos (PINHEIRO; GONÇALVES, 2001).

Ainda segundo Santos (2008), conseguir com que o objeto de aprendizagem seja interessante ao estudante assegura um certo envolvimento, pois o interesse ou prédisposição leva o sujeito a estar focado naquilo que precisa aprender. Em outras palavras, quanto mais o assunto do estudo for considerado relevante ao aluno, mais fácil será promover a construção do conhecimento.

\section{Considerações finais}

Estratégias de ensino que incluem trabalhos em grupos favorecem a coletividade; possibilitam que ações colaborativas se ampliam e se desenvolvem de forma cooperativa; oportunizam a troca de ideias, o redimensionamento dos saberes já existentes e o desenvolvimento de novos; bem como o comprometimento com a proposta e com os envolvidos. O desenvolvimento de todas as práticas envolvendo o estudo dos alimentos conseguiram transformar a sala de aula de forma muito positiva, pois viabilizaram a inovação, a criatividade, a motivação e o dinamismo no processo de ensino e de aprendizagem.

Ao término desse estudo, constatou-se um maior envolvimento das estudantes nas discussões, incentivo à pesquisa, trocas de experiências. Ademais, ocorreu uma melhor comunicação e interação entre elas, em que a ajuda mútua caracterizou o trabalho colaborativo, resultando em um entendimento muito bom acerca dos temas estudados, entre tantos outros.

A intervenção pedagógica mostrou que ensinar consiste em desenvolver ações planejadas como resposta às exigências das estudantes, e que as condições são favoráveis quando o professor conhece profundamente o assunto que ensina e as variadas técnicas didáticas que emprega. 


\section{Referências}

ANASTASIOU, L. G. C.; ALVES, L. P. Estratégias de ensinagem. In: ANASTASIOU, L. G. C., ALVES, L. P. (orgs.). Processos de ensinagem na universidade:

pressupostos para as estratégias de trabalho em aula. 3. ed. Joinville: Univille, 2004.

AUSUBEL, D. P. Aquisição e retenção de conhecimentos: uma perspectiva cognitiva. Lisboa: Plátano Edições Técnicas, 2003.

BARDIN, L. Análise de conteúdo. São Paulo: Edições 70, 2012.

BORDENAVE, J. D.; PEREIRA, A. M. Estratégias de ensino-aprendizagem. 26. ed. Petrópolis: Vozes, 2005.

COLL, C. MARTINI, E.; MAURI, T. O Construtivismo na sala de aula. 6. ed. São Paulo: Ática, 2009.

DEMO, P. Saber pensar. 2. ed. São Paulo: Cortez: Instituto Paulo Freire, 2001.

FARIA, W. Mapas conceituais: aplicações ao ensino, currículo e avaliação. São Paulo: EPU, 1995.

FONSECA, T. M. M. Ensinar e aprender: pensando a prática pedagógica. Ponta Grossa: SEED/PR, 2008. Disponível em:

http://www.diaadiaeducacao.pr.gov.br/portals/pde/arquivos/1782-6.pdf. Acesso em: 24 de abril 2016.

GIL, A. C. Didática do ensino superior. São Paulo: Atlas, 2012.

GOMEZ, M. V. Educação em rede: uma visão emancipadora. São Paulo: Cortez: Instituto Paulo Freire, 2004.

LEÃO, M. F. Ensinar química por meio de alimentos: possibilidades de promover Alfabetização Científica na Educação de Jovens e Adultos. 2014. Dissertação (Mestrado em Ensino). Programa de Pós-Graduação em Ensino. Centro Universitário UNIVATES. Lajeado, 2014.

LOPES, C. V. M.; KRÜGER, V.; DEL PINO, J. C.; SOUZA, D. O. G. Concepções de professores de Química sobre a natureza do conhecimento científico. Acta Scientiae, v. 9, p. 3-16, 2007.

LÜDKE, M.; ANDRÉ, M. E. D. A. Pesquisa em educação: abordagens qualitativas. 2. ed. São Paulo: EPU, 2013.

MOREIRA, M. A. Mapas conceituais e diagramas V. Porto Alegre: Edição do autor, 2006. Disponível em:

http://www.if.ufrgs.br/ moreira/Livro_Mapas_conceituais_e_Diagramas_V_COMPLE TO Acesso em: 15 maio 2020. 
MOREIRA, M. A. Metodologias de pesquisa em ensino. São Paulo: Editora Livraria da Física, 2011.

PHILIPPI, S. T.; CRUZ, A. T. R.; LATTERZA, A. R.; RIBEIRO, L. Pirâmide alimentar adaptada: guia para escolha dos alimentos. Revista de Nutrição, Campinas. São Paulo, v. 12, p. 65-80, 1999.

PIMENTA, S. G.; ANASTASIOU, L. G. C. Docência no ensino superior. São Paulo: Cortez, 2002.

PINHEIRO, B. M.; GONÇALVES, M. H. O processo ensino-aprendizagem. Rio de Janeiro: Editora SENAC Nacional, 2001.

SANTOS, J. C. F. Aprendizagem significativa: modalidades de aprendizagem e o papel do professor. Porto Alegre: Mediação, 2008.

THIOLLENT, M. Metodologia da pesquisa-ação. 14. ed. São Paulo: Cortez, 2005.

Submetido em: 06/12/2018. Aceito em: 13/09/2019.

Publicado em: 27/05/2020.

\section{Como referenciar este artigo:}

LEÃO, Marcelo Franco; OLIVEIRA, Eniz Conceição; GUERRA, Cecília Vieira; DEL PINO, José Claudio. Estudo dos alimentos na Educação de Jovens e Adultos e o ensino de Química. EDUCA - Revista Multidisciplinar em Educação, Porto Velho, v, 7, p. 350-368, jan./dez., 2020. DOI: 10.26568/2359-2087.2020.3704. Disponível em: http://www.periodicos.unir.br/index.php/EDUCA/issue/archive. e-ISSN: 2359-2087. 